\title{
Tissue type plasminogen activator antigen and activity in sickle cell disease
}

\author{
R B FRANCIS JR
}

\section{From the Department of Medicine, Division of Haematology, Los Angeles County University of Southern California Medical Center, Los Angeles, California, United States of America}

SUMMARY To investigate the hypothesis that diminished endothelial fibrinolysis is present in sickle cell (SS) disease plasma, tissue type plasminogen activator (t-PA) antigen titres were measured before and after a standard stimulus of endothelial t-PA release (venous occlusion of the arm), and plasma t-PA activities after venous occlusion in 33 subjects with SS disease and in 32 healthy subjects. Mean plasma t-PA antigen titres before and after venous occlusion, and mean plasma t-PA activities after venous occlusion did not differ significantly between SS patients and normal subjects. No significant differences in mean t-PA antigen and activity were observed between samples taken from inpatients being treated for acute pain crisis (18 subjects, 30 samples) and samples taken from subjects in the steady state ( 23 subjects, 26 samples). No consistent differences were seen between painful crisis and steady state samples in eight SS patients studied while in crisis and in the steady state. No correlation was observed between any fibrinolytic variable in SS patients and the overall severity of microvascular occlusive disease as measured by a standard scoring system.

It is concluded that the capacity of endothelium to synthesise and release t-PA is not impaired in SS disease, and that excessive inhibition of released t-PA, leading to reduced t-PA activity in plasma is also not a feature of SS disease, either in the steady state or during painful crisis.

Substantial evidence suggests that activation of coagulation, with increased thrombin generation and fibrin formation, occurs in patients with sickle cell (SS) disease, particularly during painful crisis. ${ }^{1-5}$ Activation of coagulation in SS patients has been attributed to an abnormal exteriorisation of thrombogenic phospholipids in the plasma membrane of SS erythrocytes ${ }^{67}$ As most of the morbidity in adults with SS disease is caused by microvascular occlusion the possible contribution of increased activation of coagulation to the pathogenesis of microvascular occlusion in SS disease is of considerable interest. Antiplatelet and anticoagulant agents have been used in an attempt to decrease the incidence and severity of microvascular occlusion in SS disease, with equivocal results. ${ }^{8-11}$ At present the role of increased activation of coagulation in the pathogenesis of microvascular occlusive disease in SS patients remains unknown.

Given that increased fibrin formation occurs in subjects with SS disease, ${ }^{45}$ it is logical to ask whether endogenous fibrinolytic activity in these subjects is sufficient to prevent accumulation of abnormal intravascular fibrin deposits. Impairment of endogen-

Accepted for publication 13 January 1988 ous fibrinolysis coexisting with increased fibrin formation would be expected to have a synergistic effect in promoting microvascular fibrin deposition. The few studies published to date disagree on whether fibrinolysis is impaired in subjects with SS disease. Mahmood $e t a l^{12}$ and Green et $a l^{13}$ reported considerably reduced fibrinolytic activity in SS patients during painful crisis but not in the steady state. In contrast, Gordon $e t$ al $^{14}$ found no evidence for impairment of fibrinolysis in SS patients either during painful crisis or: in the steady state. A major problem with these studies was the lack of specificity of the assay methods used (the dilute whole blood clot lysis time, the euglobulin clot lysis time, and the fibrin plate assay) for any one component of the fibrinolytic system. Moreover, the possible prolongation of clot lysis time assays by the increased fibrinogen concentrations characteristic of painful crisis ${ }^{1516}$ needs to be considered as a potential source of error in concluding that fibrinolysis is impaired in painful crisis.

Since the publication of these studies our understanding of and ability to measure the various components of the plasmin-dependent fibrinolytic pathway has greatly improved. It is now clear that the balance of 
endothelial production of tissue type plasminogen activator (t-PA) and its specific inhibitor (type 1 plasminogen activator inhibitor, or PAI-1) is a key determinant of overall endogenous fibrinolytic activity. ${ }^{17}$ Specific immunological and functional assays for t-PA are now available, and can be used to assess the adequacy of endothelial fibrinolysis in various disease states. ${ }^{18-20}$ The capacity of endothelium to release $\mathrm{t}-\mathrm{PA}$ can be assessed by measuring the rise in total t-PA antigen (sum of the active and inactive forms of t-PA) after a standard stimulus such as venous occlusion of the arm. The extent of inhibition of released t-PA can be assessed by measuring the amount of t-PA after venous occlusion which is present in the active (uninhibited) form. I report the application of these techniques to the study of endothelial fibrinolysis in SS patients.

\section{Patients and methods}

Thirty three SS patients and 32 controls were studied. Eighteen patients (a total of 30 samples) were studied while in painful crisis, and 23 subjects (a total of 26 samples) were studied while in the steady state: eight subjects were studied at least once both during painful crisis and in the steady state.

Any adult with haemoglobin SS or SC documented by haemoglobin electrophoresis was eligible for study. Steady state samples were obtained during routine clinic visits; steady state was defined as the absence of acute musculoskeletal pain as reported by the subject. Painful crisis samples were obtained from inpatients being treated for acute musculoskeletal pain without documented associated infection. Most of these samples were obtained within 48 hours of admission to hospital. Control subjects were normal healthy adults. No attempt was made to match control subjects and SS patients for age, sex, or race. All control subjects and all steady state SS patients were sampled in the non-fasting state between 1300 and $1600 \mathrm{~h}$. Most SS patients in painful crisis were sampled in the nonfasting state between 1000 and $1200 \mathrm{~h}$. The study was approved by the Institutional Review Board at the LAC-USC Medical Center.

Overall severity of microvascular occlusive disease in SS patients was assessed using the scoring system described by Hebbel et al. $^{21}$

After obtaining informed consent citrated blood was collected from resting subjects by standard venepuncture. A blood pressure cuff was placed on one arm and inflated to a pressure of $100 \mathrm{~mm} \mathrm{Hg}$ for exactly 10 minutes, after which a second citrated blood sample was taken from the occluded arm just before releasing the pressure. All samples were promptly centrifuged for 10 minutes at $12400 \mathrm{~g}$ at $4^{\circ} \mathrm{C}$ and the plasma stored at $-80^{\circ} \mathrm{C}$ until assayed.

t-PA antigen and activity were assayed in the euglobulin fraction of plasma by previously described methods. ${ }^{22}$

The significance of differences in mean values of $t-$ PA antigen and activity for different groups of subjects was assessed using the Wilcoxon non-paired rank sum test for variables not normally distributed. Significance of differences in t-PA antigen and activity between painful crisis and the steady state in those tested during both clinical states was assessed using the Wilcoxon signed ranks test. Correlation was assessed using simple linear regression. A $p$ value of $<0.05$ was considered to be significant. Statistical analysis was carried out using the CLINFO system (General Clinical Research Center at the Los Angeles CountyUniversity of Southern California Medical Center).

\section{Results}

Results of t-PA antigen and activity measurements for SS patients and normal controls are shown in table 1 . No significant differences in mean t-PA antigen activity before and after venous occlusion or in t-PA activity after venous occlusion were seen between normal controls and SS patients, either in painful crisis or in the steady state. A similar substantial rise in mean t-PA antigen activity with venous occlusion and a similar amount of free t-PA activity after venous occlusion was seen in controls and in SS patients, both during painful crisis and in the steady state. Mean tPA activities before venous occlusion were less than $1.0 \mathrm{ng} / \mathrm{ml}$ both in controls and SS patients (data not shown).

t-PA antigen and activity values for SS patients

Table 1 t-PA antigen and activity values in controls and in SS patients

\begin{tabular}{|c|c|c|c|}
\hline \multirow[b]{2}{*}{ Subjects/samples } & \multicolumn{2}{|c|}{ Mean (SEM) $t-P A$ antigen $(\mathrm{ng} / \mathrm{ml})$} & \multirow{2}{*}{$\frac{\text { Mean }(S E M) t-P A \text { activity }(\mathrm{ng} / \mathrm{ml})}{\text { After venous occlusion }}$} \\
\hline & Before venous occlusion & After venous occlusion & \\
\hline Controls (32/32) & $5.0(0.4)$ & $12 \cdot 8(1 \cdot 4)$ & $5.0(1.9)$ \\
\hline $\begin{array}{l}\text { As pll }(33 / 56) \\
\text { Steady state }(23 / 26) \\
\text { Crisis }(18 / 30)\end{array}$ & $\begin{array}{l}6 \cdot 6(0 \cdot 6) \\
6 \cdot 6(0 \cdot 6) \\
6 \cdot 7(1 \cdot 0)\end{array}$ & $\begin{array}{l}13 \cdot 5(1.4) \\
12 \cdot 7(1 \cdot 5) \\
14.2(2 \cdot 2)\end{array}$ & $\begin{array}{l}6 \cdot 1(1 \cdot 6) \\
5 \cdot 8(2 \cdot 4) \\
6 \cdot 4(2 \cdot 2)\end{array}$ \\
\hline
\end{tabular}


Table 2 t-PA antigen and activity values in SS patients tested during painful crisis and steady state

\begin{tabular}{|c|c|c|c|c|}
\hline \multirow[b]{2}{*}{$\begin{array}{l}\text { Case } \\
\text { No }\end{array}$} & \multirow[b]{2}{*}{ State $(n)^{*}$} & \multicolumn{2}{|c|}{$t-P A$ antigen $(\mathrm{ng} / \mathrm{ml})$} & \multirow{2}{*}{$\begin{array}{l}\text { t-PA activity ( } \mathrm{ng} / \mathrm{ml}) \\
\begin{array}{l}\text { After } \\
\text { venous occlusion }\end{array}\end{array}$} \\
\hline & & $\begin{array}{l}\text { Before } \\
\text { venous occlusion }\end{array}$ & $\begin{array}{l}\text { After } \\
\text { venous occlusion }\end{array}$ & \\
\hline $\begin{array}{l}1 \\
1 \\
2 \\
2 \\
11 \\
11 \\
12 \\
12 \\
14 \\
14 \\
21 \\
21 \\
28 \\
28 \\
33 \\
33\end{array}$ & $\begin{array}{l}\text { Crisis (2) } \\
\text { Steady state (1) } \\
\text { Crisis (4) } \\
\text { Steady state (2) } \\
\text { Crisis (4) } \\
\text { Steady state (1) } \\
\text { Crisis (5) } \\
\text { Steady state (1) } \\
\text { Crisis (1) } \\
\text { Steady state (1) } \\
\text { Crisis (2) } \\
\text { Steady state (1) } \\
\text { Crisis (1) } \\
\text { Steady state (1) } \\
\text { Crisis (1) } \\
\text { Steady state (1) }\end{array}$ & $\begin{array}{r}1 \cdot 7 \\
2 \cdot 0 \\
2 \cdot 4 \\
1 \cdot 8 \\
3 \cdot 2 \\
3 \cdot 7 \\
11 \cdot 5 \\
10 \cdot 6 \\
4 \cdot 1 \\
4 \cdot 6 \\
17 \cdot 1 \\
13 \cdot 0 \\
4 \cdot 0 \\
5 \cdot 4 \\
5 \cdot 0 \\
9 \cdot 2\end{array}$ & $\begin{array}{r}1 \cdot 9 \\
2.0 \\
5 \cdot 2 \\
3 \cdot 5 \\
7 \cdot 4 \\
8 \cdot 6 \\
23 \cdot 7 \\
13 \cdot 1 \\
14 \cdot 8 \\
7 \cdot 1 \\
24 \cdot 4 \\
17 \cdot 1 \\
9.5 \\
11.1 \\
13.6 \\
11.7\end{array}$ & $\begin{array}{c}0 \cdot 2 \\
0 \cdot 6 \\
3 \cdot 8 \\
5 \cdot 4 \\
1 \cdot 4 \\
2 \cdot 0 \\
6 \cdot 8 \\
0 \cdot 9 \\
17 \cdot 9 \\
8 \cdot 0 \\
4 \cdot 5 \\
0 \\
0 \cdot 2 \\
0 \\
1.9 \\
0\end{array}$ \\
\hline
\end{tabular}

*Number of samples; mean value is given where more than one sample was obtained.

Table 3 t-PA antigen and activity values in SS patients according to severity of microvascular occlusive disease

\begin{tabular}{|c|c|c|c|c|}
\hline \multirow{2}{*}{$\begin{array}{l}\text { Microvascular } \\
\text { occlusive } \\
\text { score }\end{array}$} & \multirow[b]{2}{*}{$n^{*}$} & \multicolumn{2}{|c|}{ Mean (SEM) t-PA antigen $(\mathrm{ng} / \mathrm{ml})$} & \multirow{2}{*}{$\begin{array}{l}\text { Mean }(S E M) t-P A \\
\text { activity }(\mathrm{ng} / \mathrm{ml})\end{array}$} \\
\hline & & $\begin{array}{l}\text { Before } \\
\text { venous occlusion }\end{array}$ & $\begin{array}{l}\text { After } \\
\text { venous occlusion }\end{array}$ & \\
\hline $\begin{aligned} & 0-1 \\
& 2-3 \\
> & 3\end{aligned}$ & $\begin{array}{c}13 / 23 \\
13 / 20 \\
4 / 8\end{array}$ & $\begin{array}{l}6.9(1.3) \\
8.0(0.7) \\
4.5(0.8)\end{array}$ & $\begin{array}{l}14 \cdot 2(2 \cdot 5) \\
16 \cdot 3(2 \cdot 2) \\
10 \cdot 0(1 \cdot 5)\end{array}$ & $\begin{array}{l}9.3(2.9) \\
5 \cdot 3(2.9) \\
2 \cdot 0(0.4)\end{array}$ \\
\hline
\end{tabular}

*Number of subjects/number of samples.

tested both in painful crisis and in the steady state are shown in table 2. t-PA antigen activity before and after venous occlusion and t-PA activity after venous occlusion were higher during painful crisis than in the steady state in three subjects, and lower during painful crisis than in the steady state in five. The differences between painful crisis and steady state values for t-PA antigen and activity in these eight subjects were not significant.

Sufficient clinical data was available to quantitate the severity of microvascular occlusive disease in 30 of the 33 SS patients. Mean t-PA antigen values and activity stratified according to overall severity of microvascular occlusive disease as measured by the scoring system of Hebbel $e t a l^{1}$ are shown in table 3. Although a trend toward decreased t-PA activity after venous occlusion with increasing severity of microvascular occlusive disease is evident, none of the differences in mean t-PA antigen and activity among patients with differing severities of microvascular occlusive disease was significant. Analysis of the data from all SS patients showed no correlation between the severity of microvascular occlusive disease and t-PA antigen or activity values.

\section{Discussion}

Our findings agree with those of the only other study reported to date in which a standardised stimulus of endothelial plasminogen activator release was used in SS patients. In that study Gordon et al found no difference in the fibrinolytic response to limited exercise or to local heat to the arm between steady state SS subjects and healthy controls. ${ }^{14}$ Many investigators may have been deterred from testing the fibrinolytic response to venous occlusion of SS patients because of the theoretical risk of causing intravascular sickling in the occluded arm. I encountered no untoward reactions other than transient local discomfort in the occluded arm in SS patients undergoing venous occlusion at $100 \mathrm{~mm} \mathrm{Hg}$ for 10 minutes. Under these conditions the venous occlusion test seems to be a safe and practical method for assessing endothelial fibrinolytic capacity in SS patients.

Ours is the first effort to apply specific assays of t-PA antigen values and activity to the investigation of fibrinolysis in SS patients. Using such assays, we have shown that endogenous endothelial fibrinolytic capacity, as measured by the rise in plasma t-PA 
antigen and activity in response to venous occlusion, is not impaired in SS disease, either during the steady state or in painful crisis. It has often been stated, but never convincingly proved, that increased fibrinogen concentrations can prolong the time to lysis in clot lysis time assays, such as the euglobulin clot lysis time and the dilute whole blood clot lysis time, thereby giving the false impression of impaired endogenous fibrinolysis. As increased fibrinogen concentrations are characteristically found in SS patients during painful crisis ${ }^{1516}$ the previous reports of impaired fibrinolysis during painful crisis based on prolonged clot lysis times ${ }^{1213}$ may therefore have been affected by this potential source of error. As neither clot lysis time nor fibrin plate methods were used in the present study, I can neither confirm nor refute this supposition.

The values of PAI-1, and hence of t-PA activity, have been reported to fluctuate diurnally, with higher values of PAI-1 (and thus lower values of t-PA activity) in the morning than in the afternoon. ${ }^{23}$ Although all control subjects and steady state SS subjects had samples taken in the afternoon, most SS patients in painful crisis has samples taken in the morning. The possibility cannot be excluded, therefore, that if SS subjects in painful crisis had had samples taken in the afternoon the mean t-PA activity for this group would have been significantly higher than for control subjects and SS patients in the steady state. At the very least, this strengthens the finding that endogenous fibrinolytic activity is not abnormally reduced in SS patients during painful crisis.

Although no correlation between the overall severity of microvascular occlusive disease and either t-PA antigen or activity values was found in SS patients, the trend toward diminished t-PA activity after venous occlusion with increasing severity of overall microvascular occlusive disease (table 3 ) is interesting. The number of subjects with severe microvascular occlusive disease - that is, a score of 3 or greater-studied was small, due in large part to the tendency of such subjects to have difficult venous access, which makes it impossible to perform the venous occlusion test. Further studies incorporating larger numbers of subjects are needed to determine whether SS patients with severe microvascular occlusive disease do, in fact, have a diminished ability to generate free t-PA activity in response to venous occlusion compared with SS patients with milder microvascular occlusive disease.

This work was supported by a grant from the Sickle Cell Disease Research Foundation of Los Angeles.

\section{References}

1 Mattii R, Weinger R, Sise HS. Coagulation, fibrinogen survival, and fibrin split products in sickle cell disease. Blood 1973;42:1004.

2 Leslie J, Langler D, Serjeant GR, Serjeant BE, Desai P, Gordon YB. Coagulation changes during the steady state in homozygous sickle-cell disease in Jamaica. Br J Haematol 1975;30:159-66.

3 Haut MJ, Cowan DH, Harris JW. Platelet function and survival in sickle cell disease. J Lab Clin Med 1973;82:44-53.

4 Leichtman DA. Brewer GJ. Elevated plasma levels of fibrinopeptide A during sickle cell anemia pain crisis-evidence for intravascular coagulation. Am J Hematol 1978;5:183-90.

5 Devine DV, Kinney TR, Thomas PF, Rosse WF, Greenberg CS Fragment D-dimer levels: an objective marker of vaso-occlusive crisis and other complications of sickle cell disease. Blood 1986;68:317-19.

6 Lubin B, Chiu D, Bastacky J, Roelofsen B, Van Deenen LLM. Abnormalities in membrane phospholipid organization in sickled erythrocytes. J Clin Invest 1981;67:1643-9.

7 Chiu D, Lubin B, Roelofsen B, Van Deenen LLM. Sickled erythrocytes accelerate clotting in vitro: an effect of abnormal membrane lipid asymmetry. Blood 1981;58:398-401.

8 Salvaggio JE, Arnold CA, Banov $\mathrm{CH}$. Long-term anticoagulation in sickle cell disease. A clinical study. $N$ Engl $\mathrm{J}$ Med 1963;269:182-6.

9 Greenberg J, Ohene-Frempong K, Halus J, Way C, Schwartz E. Trial of low doses of aspirin as prophylaxis in sickle cell disease. J Pediatr 1983;102:781-4.

10 Chaplin H, Alkjaersig N, Fletcher AP, Michael JM. Joist JH. Aspirin-dipyridamole prophylaxis of sickle cell disease pain crisis. Thromb Haemostas 1980;43:218-21.

11 Semple MJ, Al-Hasani SF, Kioy P, Savidge GF. A double-blind trial of ticlopidine in sickle cell disease. Thromb Haemostas 1984;51:303-6.

12 Mahmood A, Macintosh DM, Shaper AG. Fibrinolytic activity in the clinical crisis of sickle-cell anaemia. Br Med J 1967;3:653-4.

13 Green D, Kwaan HC, Ruiz G. Impaired fibrinolysis in sickle cell disease. Relation to crisis and infection. Thromb Diath Haem 1970;24:10-6.

14 Gordon PA, Breeze GR, Mann JR, Stuart J. Coagulation fibrinolysis in sickle cell disease. J Clin Pathol 1974;27:485-9.

15 Alkjaersig N, Fletcher A, Joist H. Chaplin H. Hemostatic alterations accompanying sickle cell pain crises. $J$ Lab Clin Med 1976;88:440-9.

16 Richardson SGN, Matthews KB, Stuart J, Geddes AM, Wilcox RM. Serial changes in coagulation and viscosity during sicklecell crisis. Br J Haematol 1979;41:95-103.

17 Loskutoff DJ. The fibrinolytic system of cultured endothelial cells: deciphering the balance between plasminogen activation and inhibition. Progress in Fibrinolysis 1985;7:15-22.

18 Wiman B, Ljungberg B, Chmielewska J, et al. The role of the fibrinolytic system in deep vein thrombosis. $J$ Lab Clin Med 1985;105:265-70

19 Korninger C, Lechner K, Niessner H, Gossinger H, Kundi M. Impaired fibrinolytic capacity predisposes for recurrence of venous thrombosis. Thromb Haemostas 1984;52:127-30.

20 Hamsten A, Blomback M, Wiman B, et al. Haemostatic function in myocardial infarction. Br Heart $J$ 1986;55:58-66.

21 Hebbel RP, Boogaerts MAB, Eaton JW, Steinberg MH. Erythrocyte adherence to endothelium in sickle-cell anemia. A possible determinant of disease severity. $N$ Engl $J$ Med 1980;302:992-5.

22 Francis RB Jr, Seyfert U. Tissue plasminogen activator antigen and activity in disseminated intravascular coagulation: clinicopathologic correlations. J Lab Clin Med 1987;110:541-8.

23 Kluft C, Verheijen JH, Rijken DC, et al. Diurnal fluctuations in the activity of the fast-acting t-PA inhibitor. Progress in Fibrinolysis 1985;7:117-23.

Requests for reprints to: Robert B Francis Jr, Raulston Research Building, Room 322, 2025 Zonal Avenue, Los Angeles, CA 90033, USA. 